\title{
Zombies Go to the Amusement Park: Entertainment, Violence, and the 21st Century Zombie in Zombieland and Left 4 Dead 2
}

\author{
Nicholas M. Kelly
}

In 2009, not one, but two pop culture products, Columbia Pictures's Zombieland and the Valve Corporation video game Left 4 Dead 2, decided to give the "zombie-apocalypse” plot a twist. Interestingly enough, they picked the same one. Zombies arrived at the amusement park. Both works still fall neatly within the zombie apocalypse genre. Their plots focus on a rag-tag band of survivors struggling to stay alive in a world overrun by the dead. However, both locate major portions of that struggle inside abandoned American fun lands. What's interesting is that these amusement parks aren't just grim, devastated ruins, backdrops used to contrast the levity of a pre-zombie world with the horror of a post-zombie one. Instead, both parks remain the pleasure centers they once were, although the "fun" is now not just in sampling the park's offerings; it is in fighting off the undead horde. In Zombieland and Left 4 Dead 2, the survivors bask in the adolescent dream of having the run of a carnival while delighting in combat against their assailants. They laugh and whoop for joy as they see the sights and ride the rides, their automatic weapons blaring. They diverge from the task of survival on the off chance of finding an unharmed Twinkie or concession stand, hoping to be the last person on Earth to savor the ambrosial flavor of junk food.

While these post-apocalyptic trips serve mostly as light-hearted entries into the zombie-apocalypse megatext, they represent a compelling site for critical consid- 
eration when examined alongside earlier zombie narratives which have received attention from the academy, notably George A. Romero's Dawn of the Dead. Through such intertextual comparison, Zombieland and Left 4 Dead 2's respective uses of the amusement park will provide an avenue through which insight may be gleaned into a spate of changes the zombie has undergone as a villain figure in past years. Part of the reason for this is that, while Left 4 Dead 2 and Zombieland do enter various zones of commerce throughout their plots, their move to place significant portions of their narratives at amusement parks seems a bid to establish the carnival as a new canonical setting for zombie combat, just as Romero did with the American mega mall in Dawn of the Dead. The mall, made famous via Dawn's scathing commentary on materialism, has become inextricably connected to the zombie apocalypse. In fact, critics have argued that Dawn's mall-based meditation was so influential that it created a situation in which modern zombie narratives are "irrevocably associated with a critique of consumer culture" (Robbins 75). Yet, in Zombieland and Left 4 Dead 2, a discussion of materialism is largely elided. Instead, the characters are incorrigible seekers of pleasure, hunters of junk food and joy, and ardent fans of the entertainment industry with propensities towards fan worship that cannot be obliterated even by a zombie apocalypse. This new generation of entertainment-fixated zombie survivors differs from their forbearers in the objects they desire to consume, yet their consumer desires remain.

In examining Left 4 Dead 2 and Zombieland medially as well as diegetically, placing them in dialogue with Dawn, we will be able to see the interrelationships between material changes in present-day life and the shifts the zombie has undergone as a villain figure in popular fiction, particularly in regards to the dynamics of violence and pleasure. Via Left 4 Dead 2 and Zombieland we will see that the metamorphosis of the zombie narrative, its move from mall-based critiques of materialism to bloody-but-playful romps across amusement parks in search of entertainment, echoes the dematerialization and digitization of the contemporary life. In short, what we will find is the zombie has transformed from a device for cultural contemplation to a figure which has become a focal point for bloody fun, a newly justified target of aggression. These changes (metonymically captured in the shift from the mall to park as zombie battleground) are symptomatic of a continued transition from physical economies and societies to immaterial and information-based ones.

First, though, it is important to distinguish that the move to the amusement park and the relocation of desire commentary are not the only drastic alterations to the Romerian zombie plot the genre has seen and a discussion of Zombieland and Left 4 Dead 2 cannot begin in earnest without first becoming familiar with 
these shifts. Indeed, in the intervening years between Dawn and Zombieland/Left 4 Dead 2 a great deal has changed with respect to the zombie's role and identity within popular entertainment. While the first appearances of the zombie in western popular consciousness (such as 1932's White Zombie) originate from the beliefs of the Voudou ${ }^{1}$ religion and cast zombies as victims of supernatural possession-pseudo-somnambulists controlled by a powerful magician or bokor-the zombie that has been adopted by most current fictions is the cannibalistic corpse pioneered by Romero. Yet many of the zombies seen in new works have begun to diverge from the Romerian zombie's tropology and narrative function. Most notable of these revisions is likely the rise of the "fast zombie" pioneered by works such as Danny Boyle's 28 Days Later, the Resident Evil films, ${ }^{2}$ and Zack Snyder's remake of Dawn. Unlike the staggering, semi-aimless stereotype of older titles, its arms outstretched, its cries for brains, these new zombies are ravenous, madly aggressive, and every bit as swift as the survivors. However, this "fast zombie" represents more than a strategy to make the zombie pose a greater threat. It shifts the zombie apocalypse on generic and diegetic terms.

As co-writer/director of Shaun of the Dead Edgar Wright argues, in its classic deployment in horror fictions the zombie horde is a "bizarre tidal, lava-like encroachment" (qtd. in Badley 49), a sluggish but inevitable force that Linda Badley notes, "resembles the slow inevitability of apathy and of death itself" (49). The fast zombie, a figure more akin to a predatory animal than mobile memento mori, shrieking in the midst of a murderous charge, not pathetically moaning while limping along, is a creature that invites no such meditations on the slow march toward death we all make. The change sees the zombie apocalypse become a narrative more akin to action films (a realm of cinema more interested in visceral reaction and glorified violence than contemplation) than a tale of creeping horror. Even a cursory glance towards "fast zombie" titles (such as Resident Evil, with its elaborate, Matrix-esque fight scenes) illustrates how the presence of the fast zombie can lead to a drastically different tonality within zombie fictions.

Second is the zombie's increasing deployment in comedic works. Although horror/comedy hybrids are a filmic vein mined as far back as Abbott and Costel$10^{3}$ and the zombie has occasionally been played for laughs as early as Dawn, ${ }^{4}$ recent years have seen a new spate of releases that put zombie violence in the service of humor. Seth Grahame-Smith's Pride and Prejudice and Zombies and 2004's Shaun of the Dead stand as clear-cut examples of this move and offer evidence of how the zombie has shambled its way into new territories. This reappropriation is not unlike the vampire's defanging and genre-shifting into a teen romance within the Twilight series. Not only is the zombie increasingly rendered as funny (a mindless fall-guy for violence gags), it is positioned within narratives 
as a creature that is fun to kill. One may look to scenes such as a moment in Shaun where the titular protagonist and his sidekick, Ed, debate which portions of Shaun's record collection to use as weapons, or Resident Evil Apocalypse's lavish fight scenes to see evidence in zombie narratives of entertainment and violence becoming bedfellows.

Unsurprisingly, Zombieland and Left 4 Dead 2 embrace both these trends. Both adopt the "fast zombie" paradigm and both ape an action/horror/comedy tone replete with slapstick-cum-gruesome scenes of carnage. One can, for instance, decapitate a foe in Left 4 Dead 2 with a frying pan and Zombieland (with a scene borrowed straight from Saturday-morning cartoon fare) sees a member of the zombie horde dispatched by a falling piano. Yet, through their uses of the amusement park, they offer something more. In his 1991 text Postmodernism, or, The Cultural Logic of Late Capitalism Fredric Jameson outlines some of the features which have come to characterize postmodernity or the age of what he terms "late capital." Jameson recounts that postmodernity has born witness to "vertiginous new dynamic[s] in international banking and the stock exchanges... new forms of media interrelationships... computers and automation, the flight of production to advanced Third World areas... [and] the crisis of traditional labor" (xxviii-xix). In Pretend We're Dead: Capitalist Monsters in American Pop Culture, Annalee Newitz posits that American monster films offer a historical reflection of the changing socio-economic landscape of the United States, writing that "as the market in images, culture, and information came to replace industrial mass production, the issues foregrounded in [monster] stories shifted" (8). The shifts of digitization, ephemeralization of the economic sphere, and the rise of a new global economic network Jameson points to are reflected in the shifts to the zombie narrative present in Left 4 Dead 2 and Zombieland.

Left 4 Dead 2 and Zombieland's new generation of zombies (as well as zombie killers) are fictive results of a world ever more abstracted and immaterial; it is vital that this relationship between current culture and changes in zombie fiction be probed as the zombie has come to inhabit an intriguing but disquieting role in the pop canon. As scholars have noted, the zombies of Romero's Dawn are complex figures, ones that invite pity as well as fear, and Romero's film frequently demonizes violence against the undead. On the other hand, zombie fictions of the contemporary era have left such pathos by the wayside. Instead, as Shawn McIntosh observes, the zombie has become something of a narrative punching bag. It is now a target upon which characters may freely lavish violence (a violence the audience may freely enjoy). Zombies now "symbolize a monster that can be killed guilt free" and it is a "no-brainer" that harm be visited upon the zombie in the name of character survival and audience pleasure (13). As we will see this 
change in fiction's approach to zombies is an unnerving one and for this reason an effort should thus be made to examine the relationship between the vicissitudes of modern life and fictive production involving the undead.

\section{Two Trips to the Amusement Park: Zombieland and Left 4 Dead 2}

Given the fairly recent releases of Left 4 Dead 2 and Zombieland (along with their status as niche genre products) a brief summary of both is necessary in order to ground a reading of the texts. Zombieland, starring Jesse Eisenberg, Woody Harrelson, Emma Stone, and Abigail Breslin, follows the cross-country journey of a self-described "paranoid shut-in" from his university dorm in Austin, Texas to the Pacific Playland amusement park in Los Angeles during a worldwide zombie pandemic. Referred to as "Columbus" (as his initial destination is his hometown Columbus, Ohio $^{5}$ ), the student soon encounters three fellow survivors: the incredibly proficient zombie killer Tallahassee (Harrelson) and the conwomen/sisters Wichita (Stone) and Little Rock (Breslin).

On the meandering journey that leads them to Pacific Playland the band encounter victims of the zombie plague in a variety of locales including knickknack shops, sprawling metropolises, and (thanks to Tallahassee's quest to find an unexpired Twinkie) grocery stores. Most significant of their stops (outside of Pacific Playland) is a visit to the mansion of actor Bill Murray, whom they encounter inside. After a practical joke gone wrong, which leads to the death of Murray (who had been disguised as a zombie so that he may go out golfing), and an enormous firefight at the zombie-infested Pacific Playland, the film ends on a markedly happy note, a romantic relationship between Columbus and Wichita established, Tallahassee's Twinkie found, and Columbus leaving the film's viewers with the advice to "enjoy the little things," his newest rule ${ }^{6}$ for surviving the zombie apocalypse.

Interestingly enough, "enjoying” the zombie apocalypse is quite literally what Left 4 Dead 2 asks players to do. Left 4 Dead 2, like its 2008 predecessor Left 4 Dead, is a first-person, team-based, online shooter which places the player in the role of one of four survivors in a zombie apocalypse: "Coach," a high school P.E. teacher, Nick, a gambler and con-man, Ellis, a naïve, young auto-mechanic, or Rochelle, a journalist. After an outbreak of the "green flu" in the Pennsylvania area, sufferers of the strange, rapidly spreading disease begin to mutate into zombie-like creatures and within weeks an apocalypse is underway. By the time Left 4 Dead 2 takes place, these "infected" have moved beyond the borders of Pennsylvania (the setting of Left 4 Dead) ${ }^{7}$ and have made their way across much of the 
eastern United States.

Left 4 Dead 2's narrative follows Coach, Nick, Rochelle, and Ellis as they undertake an arduous trek through the post-apocalyptic South on their way from Savannah, Georgia to New Orleans, the nearest city believed to be safe. The trip is divided into what Valve terms "campaigns," chapters designed to be nothing less than interactive zombie films. Valve takes the illusion so far as to fashion the loading screens for each campaign in the likeness of faux movie posters, complete with the log-in names of the players as the names of the "actors" portraying the characters. Furthermore, Left 4 Dead 2 features an A.I. program called the "Director," which monitors each player's performance and constantly adjusts the number of zombies the group faces (as well as available ammunition and first-aid supplies) in an effort to replicate the emotional pacing of a horror film and offer increased replayability to the campaigns.

The game's third campaign, "Dark Carnival," follows the survivors as they travel to and through Whispering Oaks Amusement Park, a place both Ellis and Coach visited as children. When the characters reach the park, they discover that southern rock band The Midnight Riders were set to play a show at the park before the zombies arrived; this sets in motion a plan to reach the abandoned stage and use the Riders' pyrotechnic setup to signal a nearby evacuation helicopter. ${ }^{8}$ As the group makes their way through the park, they find themselves faced with numerous zombies (or "infected") and the players must utilize the park's stillactive merry-go-rounds, roller coasters, slides, and bumper cars to dispatch their assailants. An extended portion of the campaign even takes place in Whispering Oaks's "Kiddie Land" and an abandoned tunnel of love that the characters mock as they move through it. The campaign/movie climaxes as the survivors trigger the pyrotechnics and activate a pre-recorded performance of the Midnight Riders (who, it is discovered, lip-synch), drawing a massive force of infected which must be repelled until rescue arrives and the characters are air-lifted to temporary safety.

\section{Enjoy the Little Things: Zombieland and Entertainment}

What makes Zombieland and Left 4 Dead 2 rich sites at which to direct critical attention is the ways in which they break from the monolithic influence of Romero's early zombie apocalypse films and the tropes that they employed, for the shadow cast by Romero's oeuvre is a long one indeed. Romero's Dawn has been credited with helping to establish the zombie apocalypse as a new and distinct genre and with cementing the zombie's enduring place in popular con- 
sciousness. ${ }^{9}$ Additionally, the film has gone on to generate a critical corpus likely unmatched by any single zombie narrative. Even more fascinating in regards to Zombieland and Left 4 Dead 2 is that the reason for Dawn becoming such welltrodden scholarly turf lies largely in Romero's canny mobilization of the zombie (as a mindless creature interested only in continuous consumption) and the setting of the American mega-mall as devices through which to critique consumer culture in the mid/late twentieth century. Called "one of the saddest and most damning critiques of materialism imaginable" (Paffenroth 58), critics have shown how Dawn poignantly demonstrates the dangers inherent in the desire for conspicuous consumption and how consumer culture threatens to convert us into metaphorical zombies, individuals "addicted to things that satisfy only the basest, most animal or mechanical urges of our being" (Paffenroth 55). As the characters of Dawn (the police officers Roger and Peter, the pilot, Stephen, and the news producer, Fran) plunder the Pennsylvania mall that becomes their fortress of its commodities and material markers of wealth they eventually lose both their haven and (in the case of Roger and Stephen) their lives in a meaningless pantomime of consumer behavior, perpetually looting goods that have become valueless in their post-apocalyptic world.

To note, then, that zombie fictions serve as meditations on consumer culture may seem old-hat, yet how consumer culture varies in its depiction between the 2009 works and Dawn can tell us much about historical and economic shifts in the world. We can begin to see this by first noting that while Dawn serves as a consistent invective against materialism, Zombieland's survivors rarely show any interest in material goods. When Zombieland's characters stop at former places of commerce they never bother to hoard the material markers of affluence that (as critics have observed) so interest the characters of Dawn. Zombieland's survivors loot, on occasion, but it is never status items. Instead, they favor esoteric entertainment goods: beer-dispensing helmets, liquor, or junk food. Even Tallahassee's Twinkie-lust cannot be read as materialism, but rather a desire for the pleasure of eating the last fresh one on Earth (as he tells Columbus, "Believe it or not, Twinkies have an expiration date"). An even clearer example of this material disinterest can be seen in Columbus and co.'s vandalizing of a knick-knack shop. Arriving at the store on a Twinkie hunt, the characters spread out and begin to browse. Wichita tries on hats while Columbus looks for cologne as part of a bid to woo her. After a ceramic pot is inadvertently broken, Tallahassee encourages the group to smash more of the merchandise and before long the stock is destroyed nearly wholesale. At the moment the characters seem at risk of falling into the materialistic rut that proves so dangerous in Dawn, they demonstrate their disinterest in objects (minus the entertainment they can get out of smashing them). What's 
more, the film clearly endorses this scene's politics, as Columbus treats the destruction as a revelatory event, one where Tallahassee's pleasure-centric edict to "enjoy the little things" begins to make sense to the film's high-strung hero.

This is not to say that the pursuit of postmodernity's immaterial pleasures is less dangerous than Dawn's material pursuits. Indeed, just as the materialistic impulse places Dawn's survivors in danger, so too does pleasure-seeking place Zombieland's characters in jeopardy. Timothy Roberts frames the police officers Peter and Roger's looting (or "shopping" trips) into the mall as essentially a "dereliction of duty" (80). Distracted by booty, their focus turns from survival to basking in consumer bliss. When they forget to secure their fortress, Stephen travels into danger and an unarmed and abandoned Fran is nearly bitten by a zombie who wanders into their hiding place. Kim Paffenroth similarly contends the consumerist impulse which motivates the survivors' gambit to blockade the mall makes the mission an unnecessary risk and Roger's death in the task a waste. "Loot... is all he died for," she writes, "not to save a village or secure freedom or goodness or anything noble, but just to get stuff" (58). This is mirrored (yet torqued) via Zombieland's entertainment desires. In Zombieland, such moments of danger generally stem from Tallahassee's hunt for the "spongy, yellow, delicious bastards" he seeks. Wichita's decision to activate Pacific Playland's rides similarly places the survivors in jeopardy, attracting what is easily the largest zombie threat they face.

In fact, Zombieland's narrative seem to contend that the enticement of entertainment has become perhaps even more powerful than that of the material object in that the "value" of the entertainment does not degrade in the aftermath of the apocalypse as quickly as the signifiers of wealth do. Peter Dendle writes that as "wealth" and "status" as concepts disappear in the aftermath of Dawn's zombie apocalypse the characters' interest in and display of signs of such things (fur coats, fancy dinners, and so forth) represents little more than a "pageant of affluent abundance and stability" that is "ultimately barren of meaning" (51). Yet, while Dawn characters experience boredom and dissatisfaction as they discover the hollowness of their goods, the value of cultural production in Zombieland shows little sign of erosion. The Murray mansion scenes in Zombieland firmly posit the continued influence of the entertainment industry (and even celebrity) after the collapse of civilization. When Tallahassee and Wichita first encounter Murray, Tallahassee is undeniably star-struck, gushing to the actor about his longstanding adoration. "I've been watching you since I was like, since I could masturbate," he awkwardly babbles, "not that they're connected.” Meanwhile, Columbus and Little Rock discover Murray's home theatre and put on a copy of Ghostbusters so that Columbus can "teach" Little Rock "a little something about 
Bill Murray." The film even proposes that the practice of celebrity namedropping, the value of an A-list social life, is alive and well in post-apocalyptia when Murray casually mentions he's just seen Eddie Van Halen at the Hollywood Bowl. In a macabre twist, Murray does not mean "see" Van Halen as in "in concert.” He explains, "he's a zombie,” before moving on in the conversation.

In contrast to the enduring status of cultural currency in the zombie aftermath, the value of hard currency in Zombieland is mostly erased. After Murray's death, the characters remain in the mansion overnight and, gathered around Murray's fireplace, play monopoly. Instead of game money, though, they use large stacks of cash. Like in Dawn, Zombieland signals the hollowness of money in the postapocalyptic setting, but in Zombieland money can still "purchase" pleasure by pantomiming its exchange in play. This signals a marked reconception of economics in Zombieland as opposed to Dawn. In Dawn, money's lack of worth generates angst and ennui as the characters realize they cannot exchange it for goods. In Zombieland, money still holds some purchasing power, as the characters (being more deeply situated in an ephemeral postmodern economic sphere prior to the zombie outbreak) are acclimated to exchanging currency for intangible goods.

Perhaps the most striking contrast between Dawn and Zombieland is the way that violence and pleasure intertwine as the survivors battle in the amusement park. Paffenroth observes that violence in Dawn is typically a byproduct of greed or materialism and that the film is little fan of brutality. As the characters fly over rural Pennsylvania, they spot a group of locals hunting the undead. Seeing the fight and the spread of the horde, Stephen scornfully remarks, "[t]hose rednecks are probably enjoying the whole thing." It turns out Stephen is right and a series of shots of the "rednecks" follow, attempting to justify Stephen's contempt to the audience by showing them laughing, drinking beer, and singing, stopping occasionally to take a pot shot at an approaching zombie.

Though Dawn directs scorn at the possibility anyone could enjoy a zombie apocalypse, Zombieland's visuals and plot both advance the notion that zombie killing is fun. In Zombieland, the intermingling of violence and entertainment is evident in Tallahassee's fight against the Pacific Playland horde. Using an air horn, the heavily armed Tallahassee draws the zombies to his position so that Columbus may rescue Wichita and Little Rock from a drop tower ride ${ }^{10}$ on which they are trapped. Using roller coasters, swing rides, and a booth full of carnival prizes, Tallahassee elaborately and fancifully annihilates the zombies, cackling occasionally as he goes about his business. In the end, nothing remains but a pile of zombies and Tallahassee, who twirls his pistol and gives it a loving kiss as he appraises his work. Steven Shaviro has provocatively argued that part of the visu- 
al pleasure of zombie films stems from the way they build an anticipatory tension for viewers. As moviegoers await the inevitable attack of the undead it is with a tantalizing or seductive unease, as the zombie threatens to enact a violation of both cultural and social structures, but also the human body. ${ }^{11}$ However, in Tallahasse's battle against the horde, moments of both anticipation and visual pleasure in the scene center on a human's violence against the undead.

As Tallahassee contorts into a number of dramatic poses in order to precisely angle his fire between the bars that prevent the zombies from entering the prize booth, the viewer is treated to a dramatic score and a series of slow-motion shots. Further stymieing a Shaviro-based interpretation of Tallahassee's final fight, while the viewer is in fact treated to images which build anticipation as the zombies approach the booth, it is Tallahassee who serves as the center of the spectacle. As the zombies advance and Tallahassee seals the booth, he dramatically strips off his combat vest, revealing an elaborate snakeskin jacket. Intercut with shots of the horde, we witness Tallahassee stacking magazines in a line behind him on a counter so that he may quickly turn and reload his pistols in one fluid motion. Shaviro's paradigm is shifted. We anticipate not a coming visual violation of Tallahassee's physical body but a visual presentation of Tallahassee's proficiency in the "ass-kicking business" (his stated trade).

\section{Left 4 Dead 2: Violence and Pleasure}

Diegetically, the characters of Left 4 Dead 2 manage to display many of the same motives and desires as the characters of Zombieland. As with Zombieland's survivors, they manage to avoid material lures, even when they do briefly pass through a mall on their way out of Savannah. Unlike Roger and Peter's inability to resist department-store temptations, Left 4 Dead 2's survivors almost completely ignore the delights of the shopping center and those parts of the mall that do interest them function in a similar vein as the Twinkie. As players navigate the mall Coach, the rotund bearer of the group's healthiest appetite, can be heard to pray, "Dear Lord, see us safely through our time of trial in this mall and, Lord, let the food court be okay." Like in Zombieland, consumer allure stems not from material goods, but pleasure commodities, particularly junk food, likely one of the most nutritionally ephemeral foods one could think of.

Likewise, throughout the trek through Whispering Oaks, the Left 4 Dead 2's survivors' temptation to enjoy the park is directly at odds with their chances of remaining alive. Coach will recommend they "hold out" in a corn dog stand or Ellis will plead that they pause to ride the rides ("Man, when we ever going to be 
here again?” he rationalizes). On occasion, survivors will even suggest the team take up residence within the park. The chatter illustrates that the amusement park (even without material goods) holds an analogous draw to Dawn's mall. In fact, the game encourages players to take time to enjoy the park, offering rewards called "Achievements" to those who do well at activities such as games of Whack-a-Mole, a strength-measuring challenge, and (in an interestingly-meta twist) a carnival shoot-'em-up game.

Similarly, entertainment value and the cult of celebrity persevere in Left 4 Dead 2. After discovering the Midnight Riders were to play Whispering Oaks, Coach and Ellis can be heard to express their extreme devotion to the group. Coach can be heard to remark that he has all the Riders' albums, "even their new stuff that ain't no good" and Ellis can be heard to claim that the Riders have saved his life three times (if the pyrotechnic plan works, he notes, it will be four). In fact, the only thing that shakes this adoration is the discovery of the Riders' lipsynching. Coach can be heard to exclaim, “To think, I used to like these guys!” In the world of Left 4 Dead 2 a Milli Vanilli scandal poses a bigger threat to a band's popularity than a zombie apocalypse.

Significantly, like Zombieland, Left 4 Dead 2 also makes much of utilizing the rides at the carnival as strategic tools and locations for battles against the infected. After shooting their way out of a merry-go-round, across a bumper car course, through a tunnel of love, and down a carnival slide, the survivors arrive at "The Screaming Oak," Whispering Oaks's signature roller coaster. The path to the survivors' destination involves walking along the coaster's track but opening the gate to the coaster attracts a massive number of zombies. Undaunted, and, in fact, delighted by the situation, Ellis can be heard to remark, "We have to run the coaster? Holy shit! It's Christmas!” As in Zombieland, then, violence and joy mix and the text argues that there is fun to be found in the apocalypse. The Dark Carnival adventure serves as an interesting combination of first-person shooter and first-person carnival simulator, setting it apart from zombie titles such as House of the Dead: Overkill (2009) which, though it features a brief carnival level, does not attempt to marry a carnival-going experience in conjunction with the shooting experience. $^{12}$

More importantly than diegetic terms, however, is the question of how pleasure and violence intersect in specifically medial terms. We must consider the player's trip through Whispering Oaks as well as the characters' (and the ways in which they dovetail) in order to fully understand Left 4 Dead 2. By its very nature, Left 4 Dead 2 asserts the entertainment value of killing zombies. It is, after all, a video game. While the player's task is (ostensibly) only to escape to safety, zombie/player combat is the premise of the game's mechanics. First, though, we 
will need to be appraised of two veins of extant criticism on zombie-based games which will help to frame an understanding of Left 4 Dead 2. The first such line of thinking sees zombie titles as works where pleasure is generated by the satisfaction players get from acquiring the skills necessary to achieve victory over a threat that at first seems terrifying. As Matthew Weise suggests, players learn through trial and error the necessary tools to become the last person standing in their own personalized horror film (262). Tanya Krzywinska offers a similar reading of horror games, observing that player agency and the ability to achieve control is what distinguishes horror films (a passive medium) from horror games (a medium where the player is actively involved) ("Hands-On Horror" 217). She also notes that "the leading pleasure (and frustration)" of playing zombie-based games "is built around the challenge of overcoming zombie threats" (that is to say, killing them) and that that pleasure is heightened through computer hardware's ability to render players' actions (violence) towards zombies with evergreater graphical fidelity "“Zombies in Gamespace” 162).

But because of a need for players to quickly respond to threats in actionpacked zombie games, moves that allow the player to identify with zombies or contemplate the moral or ethical complications of violence against them are frequently elided. ${ }^{13}$ Still, certain scholars have attempted to find examples in gaming where players may come to relate to zombie figures in deeper ways. Frans Mäyrä points out that playing roles such as that of an undead or "Forsaken" character in World of Warcraft allows players to experiment with becoming non-traditional protagonists, offering "opportunities for exploration into the limits and hidden sides of civilized subjectivity” (130). Ron Scott similarly asserts that playing such undead roles can lead to a sense of identification and community with outcast figures, those who perceive themselves as on the margins (181). Looking toward off-line gaming, Diane Carr and Krzywinska have suggested the immortal protagonist of Planescape Torment, “The Nameless One,” presents a more meaningful alternative to the mindless zombie figure by controlling an undead figure that bears a unique subjectivity the player may help to shape.

Let's examine, then, how Left 4 Dead 2 manages players' avenues of identification and approaches zombie violence to see how the game situates the zombie as a villain. As a team-based online title, Left 4 Dead 2 requires players to work together in order to complete its campaigns. Players must coordinate their strategies and weapon selections as well as adopt roles within their group (i.e. point person, someone to watch the rear, etc.) to best defend themselves. Without such teamwork, the players will have difficulty in staying alive and "lone wolves" are frequently overwhelmed without support from their teammates. Writing on Massively Multiplayer Online Role-Playing Games (MMORPGs) such as World of 
Warcraft, Ragnhild Tronstad has pointed out that games which demand fastpaced teamwork, role-utilization, and collective strategizing create a situation in which players become immersed in the game experience and identify with their character via integration into a position within a group (254-5). Yet, Left 4 Dead 2 does even more in the ways it actively trains players to inhabit their role within the survivor band. To help facilitate cooperation, Valve allows Left 4 Dead 2 players to communicate verbally with one another as they play, to inform each other of the location of useful items, call out incoming threats, or request assistance. However, to accommodate players without microphones, the programming of Left 4 Dead 2 also causes the characters themselves to announce such information. What is intriguing about this feature is that as the characters share information in lieu of (or alongside) the players, the game demonstrates to players how to communicate and coordinate. It trains them how to best contribute to the group. In playing Left 4 Dead 2, it is, by no means, an uncommon occurrence to hear a player call out an incoming threat or announce they have discovered a munitions cache only to have their character provide the same information at nearly the same moment. In a sense, the game programs players to fill their roles effectively, creating an identificatory dovetailing as the player learns how to inhabit their character. Similarly, as players become more familiar with the strategic benefit of protecting their teammates, the diegetic connections between the characters (bonding as they work to ensure mutual survival) is echoed in successful groups by players' desires to keep each other alive and the group working at maximum efficiency. These connections can be further reinforced if teams are comprised of friends, be they players who know each other from flesh-and-blood interactions or players who have met each other online and have established camaraderie through previous trips through the game's campaigns. ${ }^{14}$

While distinctive diegetic moves may encourage players to grow attached to a particular survivor, in Left 4 Dead 2 it is the form of the game that teaches players to literally inhabit them to best ensure survival. Even if players may not feel they are the protagonists, success depends on players' acting like them and a large part of acting like a Left 4 Dead 2 protagonist is killing zombies without hesitation (and, if Ellis's glee at the amusement park is any indication, to make sure to have fun doing so). Indeed, the game rewards players for killing, offering Achievements for various efficient or stylish forms of zombie destruction: decapitating 18 or more zombies with a golf club, for instance, nets the player an Achievement entitled "Fore."

If survival is the primary diegetic motive of the characters in Left 4 Dead 2 we must also consider how the survival motive functions for players. Two aspects of Left 4 Dead 2's play experience will allow us to better understand this: the game's 
use of "loot" and the game's Director programming. If players are killed in Left 4 Dead 2, they are unable to play until the game allows them to "respawn," to be returned to life and rejoin the fight. If the entire group dies, the players must restart the portion of the campaign they are on and try again to complete it. In both these aspects, we will see how the player's motives come not necessarily from a desire to survive, but instead from a desire to fight more zombies. The "loot" the players acquire, the various weapons and life-sustaining first-aid they can find as they play, represents a unique resource-management aspect of Left 4 Dead 2. Players must negotiate how to conserve their ammo, their first-aid kits, and explosive devices such as pipe bombs and Molotov cocktails to best ensure their chance at survival. Should players patch up a wounded teammate or save their first-aid for themselves? Does an approaching horde warrant the use of an explosive, or should the grenade be saved in case a bigger threat approaches? These are the sort of questions Left 4 Dead 2 asks. What this approach to resource management accomplishes is to generate a pseudo-economy in the game, where materials are exchanged and deployed as needed. What this does is make loot in Left 4 Dead 2 less a material good than a sort of immaterial currency. Players don't consume, they invest their loot into survival. They use their items and weapons to maximize their chance to remain in the game and minimize the risk they are removed from play. In short, they "buy" more time to kill zombies. The desired object in Left 4 Dead 2, then, is not necessarily survival, but the opportunity to inflict more violence. The presence of the Director programming offers one more illustration of how killing zombies is the clear root of pleasure in Left 4 Dead 2.

With Left 4 Dead 2, the complete annihilation of the party means repetition of content. It is the motive that presumably drives players to stay alive through a campaign. Yet, the very point of the Director is to encourage players to play campaigns over and over again by subtly altering portions of the levels each time and randomizing various item locations. This serves as an intriguing disconnect in the Left 4 Dead 2 experience. The desire to not repeat a level (due to death) is what drives the players to stay safe, but the desire to complete campaigns repeatedly is what brings players back to Left 4 Dead 2. The Director is an evidential "smoking gun" that demonstrates how the campaign format and the narrative structuring of "survival" are emotional smokescreens and justifications for violence against the undead.

But can Left 4 Dead 2 provide a meaningful zombie experience? Does it offer ways for players to identify with or feel sympathy for the undead? The game, via its "Versus Mode," does give players a chance to play as Left 4 Dead 2's "special infected," zombies that have unique capabilities compared to their rank-and-file brethren. In Versus Mode two teams of players alternate between playing zom- 
bies and playing survivors to see which team of survivors can most quickly or effectively navigate the campaign's levels as the zombie team attempts to stop them. While such a mode does enable players to step into a zombie's shoes, the game itself does little to offer identificatory avenues for the special infected. While the human protagonists sport meaningful, developed characterization, the special infected are essentially stereotypes, caricatures of the human beings they may have once been. The "Smoker" special infected, for instance, is distinguished by his hacking cough and the cloud of grey smoke he emits when he is dispatched, the "Boomer" is a belching, gurgling, parody of an obese human who either vomits bile or explodes in a goopy wave of slime when shot, and the fearsome "Tank" is an ape-like exaggeration of a muscle-head. All lack any particular personality or history that the characters bear. Furthermore, even in Versus Mode the "name of the game" is still who is the more adept at navigating the survivors. Victory goes to the team who better manages the zombie threat and while players may choose not to play as zombies (by avoiding Versus Mode) players cannot choose to play only as the zombie force. In these ways we can see how the emphasis of Left 4 Dead 2 remains thoroughly on encouraging and facilitating players' coordinated violence against the undead; while players may attempt to switch sides, any identification with the zombie is attenuated by the game's structure and the zombies' flatness.

\section{What the Move Means: Culture, Violence and the $21^{\text {st }}$ Century Zombie}

Issues of violence and entertainment, then, will serve as the staging area from which a reading of Zombieland and Left 4 Dead 2 can be concluded and the relationship between the works' amusement park setting and the recent changes in the zombie as a villain figure can be fully understood. As we have seen, Zombieland and Left 4 Dead 2 do not pose the same critique of materialism as Dawn. The mall is not the amusement park and the focus of consumer behavior in the 2009 titles revolves largely around relatively immaterial goods as opposed to physical commodities. Yet both works still offer insight into consumer behavior and their amusement parks are as symptomatic of their cultural moment as Romero's mall was of its. Both Zombieland and Left 4 Dead 2's amusement parks (as sites which metonymically represent the pursuit of entertainment and an economy of the intangible) match a contemporary period that has seen rapid and drastic social change, a period where economic and social interaction ever more involve the digital and where the developed world sees more and more of its 
business and pleasure conducted in non-physical venues. While the technologies he references may now seem somewhat dated, Mark Dery dramatically depicts the unsubstantial character of the electronic world in Escape Velocity: Cyberculture at the End of the Century:

The ephemeralization of labor and the evanescence of the commodity, in cyberculture, is paralleled by the disembodiment of the human. In growing numbers, we are spending ever greater amounts of our lives in cyberspace. The electronically disembodied are zapping E-mail around the world, typing messages back and forth in real-time 'chat,' and flocking to BBS discussion topics and UseNet newsgroups. They're lurking and flaming and ROTFLOL (Rolling on the Floor Laughing Out Loud). (6)

It is this unsubstantial (and increasingly cyber) quality of existence that Dery points to that is reflected by the amusement park and it is this increasingly abstracted and disembodied nature of postmodern life that allows for the unique dynamics between entertainment and violence found in latter zombie fiction, dynamics brought to the forefront in Zombieland and Left 4 Dead 2 where violence is literally transported into to a space of play.

In How We Became Posthuman, N. Katherine Hayles does much to decry what she sees as a growing sentiment (spurred on in part by the rapid pace of technoscientific development) of a disembodied conception of existence, a growing view that one's physical self and one's identity are not fundamentally connected. For Hayles, the threat posed by this view is the potential realization of her "nightmare," that of "a culture inhabited by posthumans who regard their bodies as fashion accessories rather than the ground being" (5). This conception of the body as little more than "meat" feeling but as a prosthesis - seems of a piece with a conception of the zombie as an entity to be killed "guilt-free," a figure upon which violence may be inflicted for entertainment's sake. Just as current digital life sees everyday interaction increasingly take place in intangible venues and through disembodying channels, we simultaneously see a creature that is a (re)animated body shifted out of personhood. It seems here of little doubt that in the cultural milieu that has produced Zombieland and Left 4 by Dead 2, a cultural milieu evermore familiar with the emotional distance of electronic mediation, one of the things on ground level that has been rendered meaningless is the misfortune of the zombie. The potential for pleasure in zombie violence is possible (on the part of both the characters and 
the audience) as a result of an ability to thoroughly de-humanize the zombie (a frightening notion given that the postmodern zombie is less often "walking dead" than "sick human") ${ }^{16}$ and table any notions of pain on its part. Entertainment and zombie violence go hand in hand in Zombieland and Left 4 Dead 2, as to kill a zombified body is not to kill a "person" or "hurt anyone." Instead, it is simply enjoying an activity at the amusement park. This, of course, is in dramatic contrast to Dawn where the violence is chastised and the humanity of the zombies frequently emphasized. ${ }^{17}$

The changes the zombie has undergone as a villain figure in recent years, its new status as a target of guilt-free violence, and the prominent use of the amusement park as a space for pleasure and bloodshed in Zombieland and Left 4 Dead 2 are byproducts of twenty-first century shifts in spheres as broad as economics, society, and technology. Simultaneously, they are the fictive results of a world whose citizens find their experience of life increasingly influenced by the changing shapes of these spheres. Consider, for instance, the "paranoid shut-in" Columbus who (prior to the apocalypse) spent the lion's share of his time gaming online and claims his unique ability to survive in the zombie wasteland is the emotional isolation his digital lifestyle afforded. In many ways, Columbus serves as a caricature of this new cyber-denizen of modern technoculture and one cannot help but wonder if Columbus would take much stock of zombie suffering in Left 4 Dead 2.

Simultaneously, it's important to highlight how the characters of Left 4 Dead 2 and Zombieland seem the result of a world where existence is frequently shaped not only by technology, but also by media. It is difficult not to note that, as the characters of both texts participate in their unabashed consumption of entertainment, multitudinous moments arise where pop-culture production shapes their understanding of their world. Consider, for instance, a stoned romp Tallahassee and Murray take through Murray's mansion, reenacting scenes from Ghostbusters. Even in a world overflowing with zombies, popular fictions of the undead remain a source of pleasure for the characters. Or, one can look to one of the first remarks Ellis makes in Left 4 Dead 2. "This some sort of nightmare?" he asks, "God damn zombie apocalypse and shit." Even when placed in a world where culture faces extinction, cultural genres guide Ellis's understanding of his world.

The danger, of course, of such emotionally distanced or mediated views of the world lies in their ability to obfuscate reality or reinforce deleterious ideologies and the notion that there's no harm done in harming a zombie is a problematic one indeed. What makes the stakes particularly high here is that the zombie has become not simply a "guilt-free" target of violence, but a violence target that can be used to circumvent the guilt of harm towards groups or individuals. By "zom- 
bifying" a person or collective, a text can attempt to sanction aggression against the now-zombified group/individual. The zombie becomes the "Everyman, or more accurately, Everymonster and thus can be inserted into any number of scenarios, from Nazi Germany... to space stations... to the old-fashioned haunted house" and posed as an ethically justified whipping-boy (McIntosh 11). This tactic can be seen throughout recent zombie fiction and one dramatic instantiation is the newly released Tea Party Zombies Must Die, a web-based title in which players may kill zombified versions of conservative politicians and pundits such as Sarah Palin or Bill O’Reilly (a number of the game's levels take place within Fox News's offices). Another current example of interactive media making such a maneuver is the Call of Duty franchise, a series which saw in both 2009 and 2010 releases which set the record for "the biggest launch in history across all forms of entertainment." "18 In titles such as World at War and Black Ops, players may take part in special "zombie" modes where enemy combatants such as the troops of Nazi Germany, Japan, or the Soviet Union are converted into zombies. Players (either alone or cooperatively) are then tasked with dispatching as many as they possibly can. These examples demonstrate how texts endeavor to use the zombie as a tool to sanction conflict and how the zombie can serve as a narrative Trojan horse in justifying violence.

This trope also appears in Zombieland, which uses the zombie as a target of justified aggression in a pivotal scene of character development for Columbus. In his bid to rescue Wichita and Little Rock at Pacific Playland Columbus is accosted by a zombie clown. Having a longstanding aversion to clowns (remarking at one point they are the only thing he fears more than zombies), Columbus is at first cowed by the creature, lamenting "it had to be a clown." However, he soon comes to realize that he can channel his fear into an act of aggression and that the zombified clown presents for him a unique opportunity to both overcome his phobia and simultaneously "be a hero."19 Thus, after pronouncing to himself "fuck this clown," he promptly brains the creature with a mallet from a carnival game.

Notably, undead clowns also feature prominently in Left 4 Dead 2 and it seems interesting that these works, whose characters are so deeply mired in the desire for entertainment, both feature the zombified clown as a threat that must ultimately be destroyed for the sake of the audience's pleasure. What's more, this figure of the zombie clown becomes a revelatory one when examined. It serves as a poignant metaphor for the complex relationship between aggression and entertainment in Left 4 Dead 2 and Zombieland, a relationship seen in much recent zombie fiction and a relationship emblematized by locating zombie violence within a space designed for the consumption of pleasure. This is because of the 
chilling fact that the zombie clown in undeath still holds the same job as in life. It remains an entertainment worker, entertaining now not carnival-goers, but, instead, survivors (and audiences) who derive pleasure from the violence against it. The zombie clown (as a forgotten worker whose suffering within the postapocalyptic entertainment economies of Left 4 Dead 2 and Zombieland remains essentially unnoticed) should serve as a reminder, then, that even though economies may seem ever more intangible, they are still intimately connected to the material realities (and hardships) which enable them.

As no shortage of scholars have observed, it was through the use of the mall and the zombie that Romero was able to probe the materialistic impulses of the twentieth century. Similarly, we can see how Zombieland and Left 4 Dead 2, through their use of reworked Romerian zombies set in American amusement parks, allow us to begin to tease out how contemporary zombie fictions reflect the cultural climate of the twenty-first century. What's more, if the zombiedespite the rampant revisions it has undergone-remains a figure inextricably tied to a critique of consumerism it should be with great historical concern that we encounter its deployment as a "worker" in the amusement park, a place that is essentially a literalized "pleasure center." For, as Jameson has argued, the rise of postmodernity is accompanied by the infiltration of the market into "all hitherto uncommodified areas" of human existence, including the unconscious (Postmodernism 36). ${ }^{20}$ Dawn has shown that part of the fear zombies generate stems from their similarity to the viewer. This, too, is a complicated notion to consider in the context of role the zombie now inhabits as a villain, as it difficult today to say if it is the cannibalistic zombie or its audience that is better described as the unfeeling thing unfazed by violence.

With irony, then, we realize in a moment where the line between audience and monster is perhaps at its most tenuous that our empathy for the zombie may well be at a historical nadir. While Left 4 Dead 2 and Zombieland give us an initial avenue through which to begin assessing the question of how social, economic, technological, and cultural realities have led to the current state of the twenty-first century zombie, it is vital that we continue to consider how it (the figure that is so nearly us, the figure that should be an object of both pity and terror) is shifted into a clown-like role, a voiceless figure made a target of violence to sate a culture's desire to remain entertained.

\section{Notes}

${ }^{1}$ For a further discussion of the history of the zombie and its relationship to the Voudou religion see Kyle Bishop’s "Raising the Dead: Unearthing the Nonliter- 
ary Origins of Zombie Cinema" or Shawn McIntosh's "The Evolution of the Zombie: The Monster That Keeps Coming Back.”

${ }^{2}$ Which, ironically, are adaptations of Capcom's Resident Evil series of video games, a collection which originally employed the "slow zombie" archetype.

${ }^{3}$ Their output includes titles such as Hold That Ghost (1941), Abbott and Costello Meet Frankenstein (1948) and Abbott and Costello Meet the Mummy (1955).

${ }^{4}$ For instance, a scene where a zombie unwittingly decapitates himself by stepping into a whirring helicopter blade was greeted by "laughter and applause" at the film's first screenings (Badley 37).

${ }^{5}$ Each of the four primary characters bases their moniker on this system.

${ }^{6}$ Throughout Zombieland Columbus dispenses his various zombie survival rules through his narration, including tips such as to always wear one's seatbelt and to make sure you always "double-tap" a zombie (shoot it twice in the head) to ensure it is dead.

${ }^{7}$ Pennsylvania, likely no coincidence, is also the setting of Dawn of the Dead.

${ }^{8}$ A note on how Left 4 Dead 2's character dialogue works: The commentary the characters make in Left 4 Dead 2 is randomly selected on each play-through of a campaign. On one occasion, one character may comment on the setting while another may a different time. However, the comments do remain consistent in tone. Coach will always remain enthusiastic towards the prospect of a food court and Ellis will always make comments in favor of southern rock, stock car racing, and so forth. As such, while they don't always say the same thing at the same time, when they talk the characters always say the same types of things. Furthermore, given that players may communicate with one another via voice chat during the game, player conversations could drown out the characters' dialogue. Nevertheless, as a barometer of the characters' goals and personalities in Left 4 Dead 2 the dialogue still serves as a useful analytic avenue.

${ }^{9}$ See Bishop (198) and McIntosh (8).

${ }^{10}$ Drop tower rides are a ring of chairs attached to a large tower which extends up into the air. The ring of chairs is mechanically lifted up to the top of the tower then repeatedly dropped, slowing down via the use of brakes before the chairs come into contact with the ground.

${ }^{11}$ See Shaviro's reading of Romero's zombie films in The Cinematic Body.

${ }^{12}$ While House of the Dead: Overkill's medial form as an on-rails shooter (a shooting game in which the player may control where their avatar aims, but not where it moves) does intriguingly remediate carnival marksmanship games, it does not offer the same meandering pleasure trip to the amusement park Left 4 Dead 2 does.

${ }^{13}$ See “Zombies in Gamespace: Form, Context, and Meaning in Zombie-Based 
Video Games” (165-166).

${ }^{14}$ Indeed, on both video game consoles such as the Xbox 360 and personal computer versions of Left 4 Dead 2, robust social media software exists to facilitate organizing games with members of players' online "friends list."

15 To borrow William Gibson's use of the term in his seminal cybertext Neuromancer (6).

${ }^{16}$ Note here the fact the zombies in both Left 4 Dead 2 and Zombieland are not "dead" but are instead disease victims (the "green flu" and "mad person disease" respectively).

${ }^{17}$ Throughout Dawn, Fran (the group's moral anchor) is shown recognizing the pitiful situation of the undead. Peter also seems aware of the zombies' lingering humanity, remarking to the other survivors, "they're us" as they watch the shambling horde.

${ }^{18}$ Stephen Totilo of video game blog Kotaku reported in November 2010 that both 2009's Call of Duty: Modern Warfare 2 and 2010's Call of Duty: Black Ops have set the record for the largest opening grosses of any entertainment title ever, Modern Warfare 2 grossing \$310 million within 24 hours of its release and Black Ops grossing $\$ 650$ million in its opening week.

${ }^{19}$ Columbus's seventeenth zombie survival rule is, "Don't be a hero," a guideline he ultimately decides is a rule that was made to eventually be broken when confronted by the clown and tasked with rescuing Wichita.

${ }^{20}$ Jameson marks two holdout regions of human freedom in The Political Unconscious, the Third World and the unconscious (92). In "Periodizing the 60's" he asserts they have been overrun (The Ideologies of Theory 513).

\section{Works Cited}

28 Days Later. Dir. Danny Boyle. Perf. Cillian Murphy, Naomie Harris, Noah Huntley. $20^{\text {th }}$ Century Fox, 2002. Film.

Badley, Linda. "Zombie Splatter Comedy from Dawn to Shaun: Cannibal Carnivalesque.” Zombie Culture: Autopsies of the Living Dead. Ed. Shawn McIntosh and Marc Leverette. Lanham, MD: Scarecrow Press, 2008. 35-54. Print.

Bishop, Kyle. "Raising the Dead: Unearthing the Nonliterary Origins of Zombie Cinema." Journal of Popular Film and Television 33.4 (2006) 196-205. Print.

Call of Duty: Black Ops. Activision, Inc., 2010. Computer software.

Call of Duty: World at War. Activision, Inc., 2008. Computer software.

Carr, Diane. "Play Dead: Genre and Affect in Silent Hill and Planescape Torment.” Game Studies 3.1 (2003): n.pag. Web. 21 May 2012.

Dawn of the Dead. Dir. George A. Romero. Perf. David Emge, Ken Foree, Scott H. Reiniger, Gaylen Ross. Anchor Bay Entertainment, 1978. Film. 
Dawn of the Dead. Dir. Zack Snyder. Perf. Sarah Polley, Ving Rhames, Jake Weber, Mekhi Phifer. Universal Studios, 2004. Film.

Dery, Mark. Escape Velocity: Cyberculture at the End of the Century. New York: Grove Press, 1996. Print.

Dendle, Peter. "The Zombie as Barometer of Cultural Anxiety." Monsters and the Monstrous: Myths and Metaphors of Enduring Evil. Ed. Niall Scott. Amsterdam: Editions Rodopi, 2007. 45-57. Print.

Gibson, William. Neuromancer. New York: Ace Books, 1984. Print.

Grahame-Smith, Seth. Pride and Prejudice and Zombies. Philadelphia: Quirk, 2009. Print.

Hayles, N. Katherine. How We Became Posthuman: Virtual Bodies in Cybernetics, Literature, and Informatics. Chicago: University of Chicago Press, 1999. Print.

House of the Dead: Overkill. Sega, 2009. Computer software.

Jameson, Fredric. The Ideologies of Theory. London: Verso, 2009. Print.

- . The Political Unconscious: Narrative as a Socially Symbolic Act. Ithaca: Cornell UP, $1982 . \quad$ Print.

—. Postmodernism, or, The Cultural Logic of Late Capitalism. Durham: Duke UP, 1991. Print.

Krzywinska, Tanya. "Hands-On Horror." ScreenPlay: Cinema/Videogames/Interfaces. Ed. Geoff King andTanya Krzywinska. London: Wallflower Press, 2002. 206-24. Print.

—. "Zombies in Gamespace: Form, Context, and Meaning in Zombie-Based Video Games.” Zombie Culture: Autopsies of the Living Dead. Ed. Shawn McIntosh and Marc Leverette. Lanham, MD: The Scarecrow Press, 2008. 153-68. Print.

Left 4 Dead. Valve Corporation, 2008. Computer software.

Left 4 Dead 2. Valve Corporation, 2009. Computer software.

Mäyrä, Frans. "From the Demonic Tradition to Art-Evil in Digital Games: Monstrous Pleasures in The Lord of the Rings Online." Ringbearers: The Lord of the Rings Online as Intertextual Narrative. Ed. Tanya Krzywinska, Esther MacCallum-Stewart and Justin Parsler. Manchester: Manchester UP, 2011. 111-35.

Print.

McIntosh, Shawn. "The Evolution of the Zombie: The Monster That Keeps Coming Back.” Zombie Culture: Autopsies of the Living Dead. Ed. Shawn McIntosh and Marc Leverette. Lanham, MD: The Scarecrow Press, 2008. 1-18. Print.

Newitz, Annalee. Pretend We're Dead: Capitalist Monsters in American Pop Culture. Durham: Duke UP, 2006. Print. 
Paffenroth, Kim. Gospel of the Living Dead: George Romero's Visions of Hell on Earth. Waco: Baylor UP, 2006. Print.

Resident Evil: Apocalypse. Dir. Alexander Witt. Perf. Milla Jovovich, Shaun Austin-Olsen, Mike Epps, Megan Fahlenbock. Sony Pictures, 2004. Film.

Roberts, Timothy. "Dead Ends: The Spectre of Elitism in the Zombie Film." Philament 9.1 (2006) 75-88. Print.

Scott, Ron. “'Now I'm Feeling Zombiefied’: Playing the Zombie Online.” Zombie Culture: Autopsies of the Living Dead. Ed. Shawn McIntosh and Marc Leverette. Lanham, MD: The Scarecrow Press, 2008. 169-84. Print.

Shaun of the Dead. Dir. Edgar Wright. Perf. Simon Pegg, Kate Ashfield, Lucy Davis, Nick Frost. Universal, 2004. DVD.

Shaviro, Steven. The Cinematic Body. Minneapolis: University of Minnesota Press, 1993. Print.

Tea Party Zombies Must Die. StarvingEyes Advergaming, 2011. Web. 25 Sep. 2011.

Totilo, Stephen. "Call of Duty: Black Ops Continuing Domination Over Books, Games, Movies, President Bush.” Kotaku. Gawker Media, 18 Nov. 2010. Web. 1 Dec. 2010.

Tronstad, Ragnhild. "Character Identification in World of Warcraft: The Relationship between Capacity and Appearance.” Digital Culture, Play, and Identity: a World of Warcraft Reader. Ed. Hilde G. Corneliussen and Jill Walker Rettberg. Cambridge: MIT Press, 2008. 249-64. Print.

World of Warcraft. Blizzard Entertainment, 2004. Computer software.

Zombieland. Dir. Ruben Fleischer. Perf. Woody Harrelson, Jesse Eisenberg, Emma Stone, Abigail Breslin. Columbia Pictures, 2009. DVD. 